\title{
MOLECULARLY IMPRINTED POLYMER NANOPARTICLES AS POTENTIAL TOOL FOR IMMUNOHISTOCHEMISTRY
}

\author{
Jaroslava BEZDEKOVA, Kristyna TOMECKOVA, Kristyna PAVELICOVA, Kristyna ZEMANKOVA, \\ Marketa VACULOVICOVA
}

\author{
Department of Chemistry and Biochemistry, Mendel University in Brno, Brno, Czech Republic, EU, \\ bezdekovajar@gmail.com
}

https://doi.org/10.37904/nanocon.2020.3751

\begin{abstract}
Immunohistochemistry $(\mathrm{IHC})$ is a powerful technique enabling visualization/detection of cellular components (e.g. overexpressed proteins) in tissue samples and thus ensuring timely recognition of a wide range of diseases. Nowadays, antibodies labelled by different kinds of sensing probes are routinely used for selective recognition of $\mathrm{IHC}$ markers. However, antibodies as bio-macromolecules have a number of drawbacks including physical and (bio) chemical instability or large production cost. Therefore, the design and synthesis of artificial antibodies that are able to bind a target molecule with similar affinity and specificity have become a long-term goal in a range of scientific branches. In this work, molecularly imprinted polymer nanoparticles (MIPs), as antibody mimics, were used as IHC agents. Specifically, polydopamine MIP nanoparticles doped with metal ions and selective for metallothionein as potential IHC marker were developed and combined with laser ablation ICP-MS. This novel approach can significantly enhance the abilities of IHC analysis and solve issues connected with the low stability of antibodies.
\end{abstract}

Keywords: Molecularly imprinted polymers, immunohistochemistry, metallothionein

\section{INTRODUCTION}

Immunohistochemistry $(\mathrm{IHC})$ is a laboratory method, indispensable in clinical diagnostics for identification and classification of various diseases. Very important role IHC plays also in research where is utilized to the investigation of many biological processes e.g. visualization of proteins expressed on the cell surface, characterization of protein interactions, observe the distribution and localization of specific cell structures etc. [1].

Among the most common methods for tissue samples visualization belongs fluorescence microscopy based on visualization of the fluorescent probes or light microscopy based on visualization of chromogenic substrate created by enzymatic probes [2]. However, these methods have limited sensitivity and do not allow visualizing high number of analytes in the same tissue section. Recently, visualization through LA-ICP-MS (Laser Ablation Inductively Coupled Plasma Mass Spectrometry) based on conjugation with elemental tags have become a promising alternative $[3,4]$.

In contrast to the above mention methods, LA-ICP-MS can be used for the multiplex analysis. By this method, it is possible to determine several tissue antigens simultaneously using recognition elements containing various metal ions or rare elements [5]. Moreover, LA-ICP-MS enables measurement of trace naive elements in tissues which also play a significant role in cancer diagnostics. Because it was demonstrated that the levels of some trace elements are significantly elevated in cancer tissue [6].

Ordinarily, analyte within the tissue is specifically recognized by a primary antibody labelled with an appropriate probe (fluorescent, enzyme, metal). However, antibodies have several disadvantages e.g. they have limited 
physical and (bio)chemical stability, sometimes it is difficult to obtain antibodies against chosen targets, and their production in large quantities is demanding and expensive. Therefore, design and synthesis of chemical alternatives of antibodies are extensively studied. One possible way is the use of molecularly imprinted polymers (MIPs) [7]. MIPs are synthetic materials with a defined spatial arrangement of the free functional groups of the polymer chains which enable them to specifically recognize target molecule. The process of MIP synthesis is quite simple. Initially, template (imprinted molecule) and functional monomers form a complex through either covalent or noncovalent interactions. Subsequently, the copolymerization process with crosslinking monomers is initiated which leads to the creation of polymer. Removal of the template molecules from the three-dimensional polymer network enable to the creation of imprinted binding sites complementary to the template in terms of size, shape, and positioning of functional groups.

In this work, polydopamine MIP nanoparticles, doped with copper ions, selective for metallothionein (MT) were prepared. MT is usually expressed in human cells at low concentration levels however its expression is increased during oxidative stress to protect the cells against cytotoxicity, radiation and/or DNA damage. In various human tumors (e.g. breast, colon, kidney, liver, lung, etc.) an increased expression of MT was determined and therefore nowadays many studies are focused on the application of MT as potential IHC marker. Synthetized MIP particles were subsequently combined with LA-ICP-MS as a visualization method for IHC. This completely novel approach enables solve issues connected with the poor stability and high production-cost of antibodies and significantly enhance the abilities of IHC analysis. For better imagination, the idea of the suggested approach is shown in Figure 1.

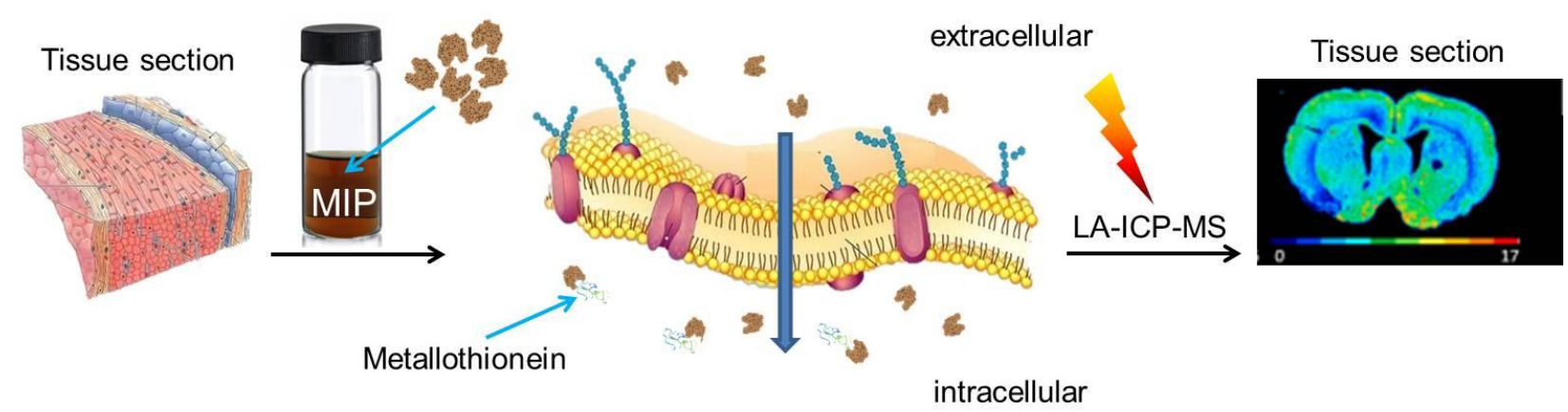

Figure 1 The tissue section is incubated with prepared MIP particles. Follows penetration of MIP particles into the cell where they selectively recognize and bind MT. Unbound MIP particles are washed out and subsequent LA-ICP-MS enables to detect copper ions in MIP particles which leads to highlighted area of tissue with increased metallothionein concentration

\section{MATERIALS AND METHODS}

\subsection{Materials}

Dopamine hydrochloride, Trizma base (TRIS), sodium dodecyl sulfate (SDS), sodium tetraborate decahydrate, copper(II)sulfate pentahydrate $\left(\mathrm{CuSO}_{4} \cdot 5 \mathrm{H}_{2} \mathrm{O}\right)$ and acetic acid ( $\mathrm{HAc}$ ) were purchased from Sigma-Aldrich (St. Louis, MO, USA). Ammonia solution $25 \%$ and ethanol absolute were obtained from Merck (Darmstadt, Germany). Metallothionein-2 from rabbit liver (MT-2) was purchased from Enzo Life Sciences (Farmingdale, NY, USA). Deionized water was obtained from a Millipore (Milli-Q) purification system at a resistivity of 18.2 $\mathrm{M} \Omega \cdot \mathrm{cm}$. All chemicals and solvents were of analytical or HPLC grade and used without further purification.

\subsection{Preparation of MIPs and non-imprinted polymers (NIPs)}

MIP particles are synthetized in parallel with NIP particles which are chemically identical but are synthesized without the presence of the template molecule and therefore, they lack affinity to MT. These particles are used 
for the monitoring of non-selective interactions. In both cases, dopamine was used as a functional monomer because of its ability to undergo fast self-polymerization in the presence of oxygen and alkaline environment.

The MIPs were synthesized through the oxidation and self-polymerization of dopamine molecules in a solution consisting of water, ethanol and ammonia at room temperature in the presence of template molecules (MT-2) and $\mathrm{Cu}(\mathrm{II})$ ions. 1,2 or $4 \mathrm{mg}$ of $\mathrm{Cu}$ (II) ions were dissolved in solution consisting of $900 \mu \mathrm{l}$ of deionized water, $400 \mu \mathrm{l}$ of absolute ethanol and $30 \mu \mathrm{l}$ of ammonia aqueous solution $(25 \%)$ and stirring at $30{ }^{\circ} \mathrm{C}$ for $45 \mathrm{~min}$. A $100 \mu \mathrm{l}$ of an aqueous solution of dopamine hydrochloride $(5 \mathrm{mg} / \mathrm{ml})$ and MT-2 $(1 \mathrm{mg} / \mathrm{ml})$ was quickly injected into this solution. It was observed that the solution color turned to pale yellow immediately and then gradually changed to black after $1 \mathrm{~h}$. After $24 \mathrm{~h}$, the created MIPs were separated by centrifugation $\left(13,500 \mathrm{rpm}, 25^{\circ} \mathrm{C}\right.$, $30 \mathrm{~min}$ ) and washed with $3 \% \mathrm{HAc}$ twice and once with $10 \mathrm{mM}$ TRIS pH 7.4. NIPs were prepared by the same protocol but without the presence of template (MT-2).

\subsection{Isolation of MT-2 from by MIPs}

$50 \mu \mathrm{l} \mathrm{MIP}$ or NIP particles suspended in $10 \mathrm{mM}$ TRIS pH 7.4 were mixed with $50 \mu \mathrm{l} \mathrm{MT-2}(0.04,0.08,0.16$ or $0.33 \mathrm{mg} / \mathrm{ml})$ and incubated with constant stirring $\left(30^{\circ} \mathrm{C}, 500 \mathrm{rpm}\right)$ for $(10,20,30,40$ or $50 \mathrm{~min})$. Then the mixture was centrifuged $\left(13,500 \mathrm{rpm}, 25^{\circ} \mathrm{C}, 5 \mathrm{~min}\right.$ ) and the supernatant was measured by MEKC (micellar electrokinetic chromatography) with UV-vis detection or MIP/NIP particles were washed with MilliQ water and sonicated by $(5,10,15,20 \mathrm{~min})$ which led to release of bound analyte followed by analysis by MECK with UVvis detection.

Quantification of MT-2 was performed by capillary electrophoresis (CE) instrument 7100 (Agilent Technologies, Germany) with absorbance detection at a wavelength of $200 \mathrm{~nm}$. Fused silica capillary with an internal diameter of $75 \mu \mathrm{m}$, with a total length of $64.5 \mathrm{~cm}$ and an effective length of $56 \mathrm{~cm}$ was used. The sample was introduced hydrodynamically at 50 mbar for $5 \mathrm{~s}$ and a separation voltage of $30 \mathrm{kV}$ was applied. A background electrolyte (BGE) was composed of $40 \mathrm{mM}$ sodium borate buffer, $60 \mathrm{mM}$ SDS at pH 9.8. Before the analysis, the capillary was washed for 60 seconds using BGE.

\section{RESULTS AND DISCUSSION}

\subsection{Characterization of obtained MIP/NIP particles}

MIP particles were synthesized by the oxidation and self-polymerization of dopamine in a mixture containing water, ethanol, and ammonia, which led to the creation of spherical nanoparticles. Their size could be easily controlled by tuning the molar ratio of ammonia and dopamine. The size of MIP and NIP particles was determined by dynamic light scattering using a Zetasizer Nano from Malvern Instruments Ltd (Malvern, UK). Average hydrodynamic size in $10 \mathrm{mM}$ TRIS buffer $\mathrm{pH} 7.4$ was: $175 \mathrm{~nm}$ for MIP and $170 \mathrm{~nm}$ for NIP. The homogeneity of prepared particles is demonstrated by relatively low polydispersity: in case of MIP 0.22 and 0.21 in case of NIP.

\subsection{Optimization of $\mathrm{Cu}$ ions concentration}

The LA-ICP-MS is technique capable of quantitative determination of elements. In this work, the copper contained in MIP/NIP particles was determined. However, firstly, it was necessary to carry out the experiment that reveals the amount of copper ions which can be added to the polymeric mixture without the loss of efficiency of resulting MIPs. Three different concentrations of $\mathrm{CuSO}_{4} \cdot 5 \mathrm{H}_{2} \mathrm{O}$ were added into the polymeric mixture, specifically 1,2 and $4 \mathrm{mg} / \mathrm{ml}$. Subsequently, the ability of obtained particles to selectively recognize MT-2 was studied. It was found out that MIP particles prepared with a concentration of $2 \mathrm{mg} / \mathrm{ml}$ of $\mathrm{Cu}$ (II) ions have the best efficiency and simultaneously is this concentration sufficient for LA-ICP-MS determination. Measured data are shown in Figure 2 A. 


\subsection{Optimization of binding time}

Further, adsorption kinetics of MIP/NIP particles was investigated in the time range from 10 to 50 min in 10 min intervals. The curve of adsorption kinetics is shown in Figure 2 B. From obtained data, it is seen that initially the binding capability is high due to a large number of empty binding sites available to the target protein. Saturation of all binding sites of MIP was achieved after 20 min of incubation and therefore this incubation time was selected as optimal.
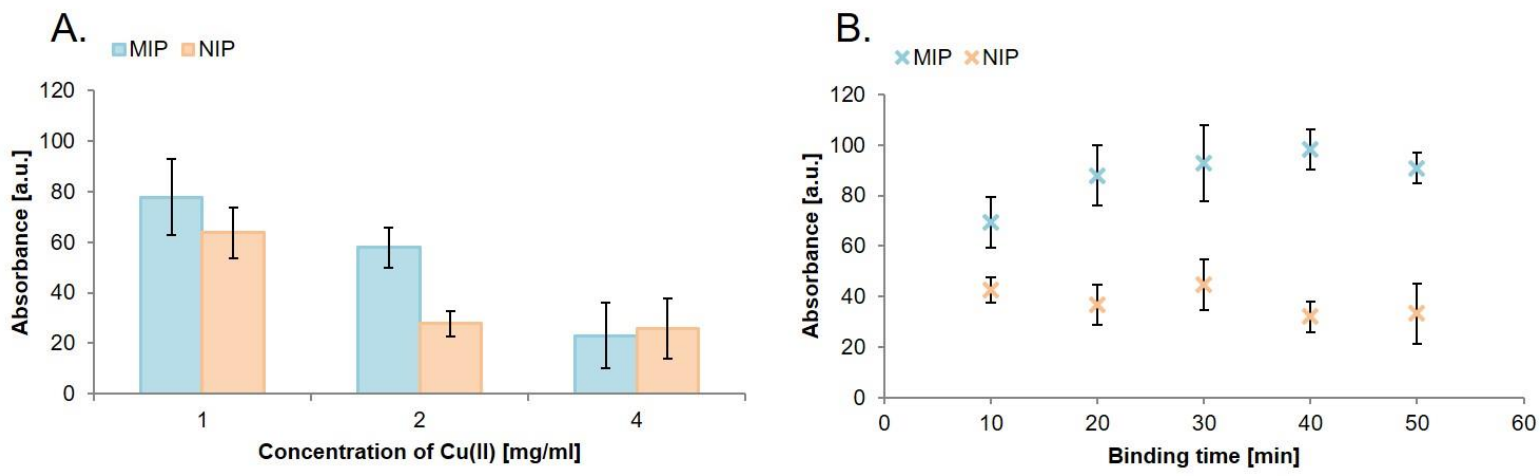

Figure 2 A. Optimization of copper ions concentration; B. The curve of absorption kinetic; *Error bars represent a deviation of three repeated measurements

\subsection{Optimization of sonication time}

In the above mention experiments, the MT-2 concentration was determined indirectly by measuring of unbound MT-2 in the supernatant. However, for measuring the calibration curve, it was necessary to release the bound MT-2 from MIP binding sites. The release of MT-2 was carried out by sonication of prepared MIPs. It this experiment, the optimal sonication time was investigated. As shown in Figure $\mathbf{3}$ A, 10 minutes of sonication enabled to release the majority of bound protein but did not cause their destruction therefore 10 minute sonication was chosen as optimal.

\subsection{Calibration curve}

To evaluate the binding properties of MIP/NIP particles, an experiment based on incubation of MIP/NIP particles in different initial concentrations of MT-2 $(0.33,0.165,0.083,0.041 \mathrm{mg} / \mathrm{ml})$ was carried out. Obtained data are shown in Figure 3 B. All experiments focused on the optimization of MIP particles preparation were performed by using CE with UV-vis detection because this method provides more detailed information about the interaction of the analyte with MIP/NIP particles. Optimized MIP particles can be subsequently applied in IHC and detected by LA-ICP-MS which ensures a lower detection limit in comparison with CE and provides closer information about the study tissue section.
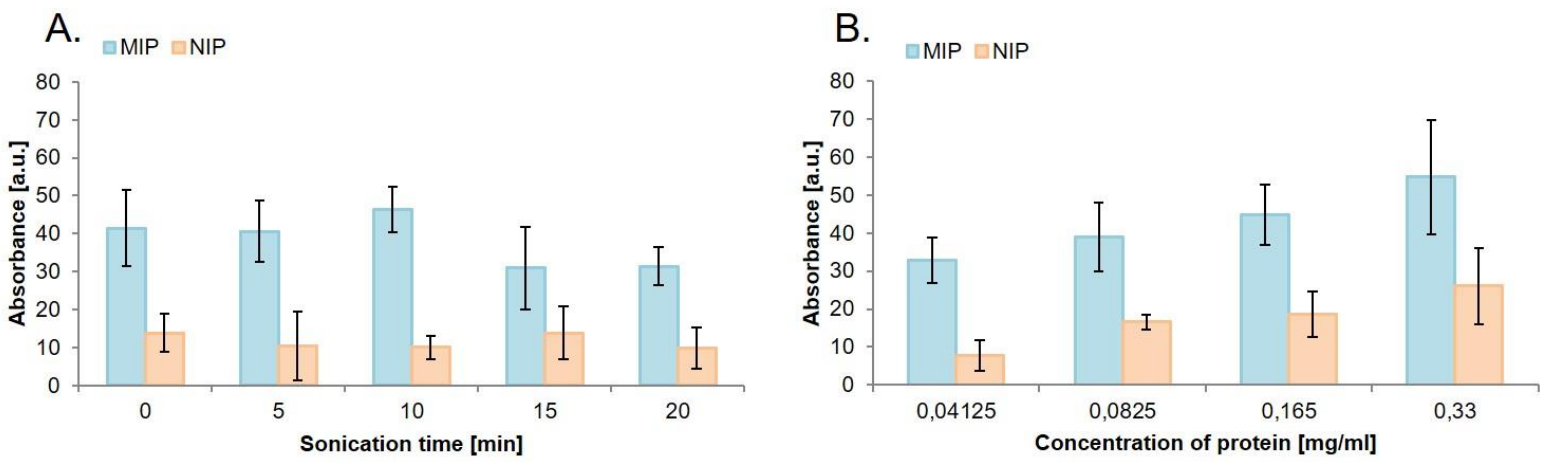

Figure 3 A. Optimization of sonication time necessary for the release of bind analyte; B. The calibration curve. *Error bars represent a deviation of three repeated measurements 


\section{CONCLUSION}

In this work, MIP particles were prepared for the first time to be used as an artificial recognition element for IHC. The technique of non-covalent molecular imprinting was used in the preparation process. Dopamine was used as a functional monomer. The experiments focused on the binding time and adsorption efficiency of created MIP particles was carried out by using CE with UV-vis detection because this method provides more detail information about the interaction between MIP particles and MT (e.g. nonspecific sorption). Thus, optimized MIP particles can be applied in IHC with detection by LA-ICP-MS.

\section{ACKNOWLEDGEMENTS}

This research was carried out under the project CEITEC 2020 (LQ1601) with financial support from the Ministry of Education, Youth and Sports of the Czech Republic under the National Sustainability Programme II.

\section{REFERENCES}

[1] AZIZ, S. A., MEHTA, R. Immunohistochemistry: Overview, its potential, and challenges. Technical aspects of toxicological immunohistochemistry. In: Aziz S., Mehta R. (eds) Technical Aspects of Toxicological Immunohistochemistry. New York: Springer, 2016, pp. 1-4.

[2] DURAIYAN, J., GOVINDARAJAN, R., KALIYAPPAN, K., PALANISAMY, M. Applications of immunohistochemistry. Journal of pharmacy \& bioallied sciences. 2012, vol. 4. no. Suppl 2, p. S307.

[3] SEUMA, J., BUNCH, J., COX, A., MCLEOD, C., BELL, J., MURRAY, C. Combination of immunohistochemistry and laser ablation icp mass spectrometry for imaging of cancer biomarkers. Proteomics. 2008, vol. 8. no. 18, pp. 3775-3784.

[4] PUGH, J., COX, A., MCLEOD, C., BUNCH, J., WHITBY, B., GORDON, B., KALBER, T., WHITE, E. A novel calibration strategy for analysis and imaging of biological thin sections by laser ablation inductively coupled plasma mass spectrometry. Journal of Analytical Atomic Spectrometry. 2011, vol. 26. no. 8, pp. 1667-1673.

[5] GIESEN, C., MAIRINGER, T., KHOURY, L., WAENTIG, L., JAKUBOWSKI, N., PANNE, U. Multiplexed immunohistochemical detection of tumor markers in breast cancer tissue using laser ablation inductively coupled plasma mass spectrometry. Analytical chemistry. 2011, vol. 83. no. 21, pp. 8177-8183.

[6] RIZK, S. L., SKY-PECK, H. H. Comparison between concentrations of trace elements in normal and neoplastic human breast tissue. Cancer research. 1984, vol. 44. no. 11, pp. 5390-5394.

[7] HAUPT, K., MEDINA RANGEL, P. X., BUI, B. T. S. Molecularly imprinted polymers: Antibody mimics for bioimaging and therapy. Chemical Reviews. 2020, vol. 120 no. 17, pp. 9554-9582. 